\title{
Antiseptic mouthwash, the nitrate-nitrite- nitric oxide pathway, and hospital mortality: a hypothesis generating review
}

Stijn Blot ${ }^{1,2^{*}}$ (i)

(c) 2020 Springer-Verlag GmbH Germany, part of Springer Nature

\begin{abstract}
Meta-analyses and several large cohort studies have demonstrated that antiseptic mouthwashes are associated with mortality in hospitalized patients. A clear pathogenic mechanism is lacking, leading to controversy and a reluctance to abandon or limit the use of antiseptic mouthwashes. Here, we generate the hypothesis that a disturbance in nitric oxide homeostasis by antiseptic mouthwashes may be responsible for the observed increase in mortality risk. Nitric oxide is essential in multiple physiological processes, and a reduction in nitric oxide bioavailability is associated with the occurrence or worsening of pathologies, such as atherosclerosis, diabetes, and sepsis. Oral facultative anaerobic bacteria are essential for the enterosalivary nitrate-nitrite-nitric oxide pathway due to their capacity to reduce nitrate to nitrite. Nitrate originates from dietary sources or from the active uptake by salivary glands of circulating nitrate, which is then excreted in the saliva. Because antiseptic mouthwashes eradicate the oral bacterial flora, this nitric oxide-generating pathway is abolished, which may result in nitric oxide-deficient conditions potentially leading to life-threatening complications such as ischaemic heart events or sepsis.
\end{abstract}

Keywords: Antiseptic mouthwash, Chlorhexidine, Oral care, Mortality, Nitric oxide, Enterosalivary pathway, Nitratenitrite-NO pathway

\section{Introduction}

Oral care is essential to maintaining or improving oral health [1]. The Adult Dental Health Survey indicates that mouthwash is regularly used by $31 \%$ of dentate adults [2]. Mouthwashes are used by healthy individuals for a variety of reasons, such as to freshen breath or as part of a healthy lifestyle [3]. Poor oral health is associated with bad outcomes due to an increased risk of systemic and respiratory complications [4]. Therefore, antiseptic mouthwashes are given to a variety of hospitalized

\footnotetext{
*Correspondence: stijn.blot@UGent.be

${ }^{1}$ Department of Internal Medicine and Pediatrics, Faculty of Medicine and Health Sciences, Ghent University, Campus UZ Gent, Corneel Heymanslaan 10, 9000 Ghent, Belgium

Full author information is available at the end of the article
}

patients and nursing home residents to maintain or restore oral health [5-11]. In ICUs, chlorhexidine mouthwashes are recommended to prevent nosocomial and/ or ventilator-associated pneumonia, though this is based on weak evidence [12-15]. Importantly, in the slipstream of these recommendations, chlorhexidine oral care has been increasingly applied in non-ventilated ICU patients, though this also lacks documented evidence. Consequently, oral chlorhexidine use has become general practice in many ICUs, driven mainly by the presumed clinical benefits and presumed absence of adverse events.

\section{Problem outline: Is chlorhexidine oral care harmful?}

Reports questioning the safety of chlorhexidine for oral care have accumulated in recent years. A 2014 meta-analysis including 12 randomized controlled trials comprising 3630 ICU patients found a trend towards an increased risk of mortality with the use of oral chlorhexidine

\section{重


[relative risk (RR) 1.13, 95\% confidence interval (CI) 0.99-1.28] [16]. Another 2014 meta-analysis exclusively considered patients in general ICUs (excluding specialty units such as those for transplantion or heart surgery) [17]. Pooled results of 11 randomized controlled trials including 2618 patients found that oral chlorhexidine is associated with an increase in mortality [odds ratio (OR) 1.25, 95\% CI 1.05-1.5]. In 2016, Klompas et al. reported that oral chlorhexidine use increased ventilator mortality among 5539 mechanically ventilated patients in a singlecentre retrospective study [hazard ratio (HR) 1.63, 95\% CI 1.15-2.31] [18]. In the absence of conclusive safety data, the 2017 International ERS/ESICM/ESCMID/ ALAT Guidelines issued regarding the management of ventilator-associated pneumonia withheld recommendations concerning chlorhexidine oral care [19]. In 2018, a hospital-wide cohort study of 82,274 patients, including 11,139 who received chlorhexidine oral care, showed that this practice was independently associated with mortality in either low-level chlorhexidine exposure $(\leq 300 \mathrm{mg}$ cumulative dose, the equivalent of a single bottle of oral care mouthwash; OR 2.61, 95\% CI 2.32-2.92) or highlevel exposure (>300 mg cumulative dose; OR 2.73, 95\% CI 2.35-3.16) [20]. More recently, Parreco et al. reported a multicentre study comprised of data from 186 US hospitals over a 2-year period [21]. The cohort included 64,904 ICU patients, 14,333 of whom were exposed to chlorhexidine oral care. After controlling for confounding factors, chlorhexidine oral care appeared an independent risk factor for mortality (OR 1.25, 95\% CI 1.16-1.34).

A plausible explanation for the increased risk of death among patients exposed to oral chlorhexidine is still lacking. Chlorhexidine allergy is a growing concern in healthcare, and exposure of the mucosa to chlorhexidine can result in anaphylactic shock [22-25]. However, such an event is rare and can hardly be held responsible for a phenomenon that has remained under the radar for decades [23-25]. Alternatively, higher concentrations of chlorhexidine in mouthwash solutions (i.e., $2 \%$ instead of the more commonly used $0.05 \%$ or $0.12 \%$ ) have been associated with ulceration of the oral mucosa [26]. In view of this, Bellissimo-Rodrigues et al. conducted a post hoc analysis assessing dental care in the ICU in a randomized controlled trial of patients receiving a chlorhexidine-based oral care protocol [27]. The authors proposed chlorhexidine-induced oral mucositis as a pathway to mortality (adjusted OR 6.14, 95\% CI 1.98-19.08). However, their analysis seemed biased, as higher chlorhexidine concentrations were applied in sicker patients ( $2 \%$ vs. $0.12 \%)$, constituting a trigger for mucositis. In addition,

\section{Take-home message}

Oral bacteria are essential in nitric oxide homeostasis. Eradicating the oral microbiome by antiseptic mouthwashes may result in a state of deficient nitric oxide bio-availability, putting patients at risk for potentially life-threatening complications. These insights constitute a pathogenic mechanism bridging antiseptic mouthwashes with mortality and plea against profuse antiseptic mouthwash use in hospitalized patients.

adjustments for disease severity were made on admission data, and oral mucositis may have occurred later during the disease course. Finally, silent microaspiration of chlorhexidine into the deeper airways of intubated patients has been presumed to trigger pulmonary complications. This hypothesis was based on experimental data in rats exhibiting pulmonary toxicity following considerable chlorhexidine instillation, and a single case report of a confused elderly individual who ingested a bottle of mouthwash, vomited, and aspirated the gastric contents, leading to fatal acute respiratory distress syndrome [28, 29]. Two factors make this hypothesis unlikely. First, both studies reported chlorhexidine exposure in the lung tissue at levels far beyond what can be assumed on the basis of silent microaspiration. Second, the observed association with mortality appearing higher in non-critically (and therefore non-intubated) patients annihilated the microaspiration hypothesis [20]. Nonetheless, macroaspiration of larger amounts of chlorhexidine in nonintubated patients with swallowing disorders (e.g. stroke patients) cannot be ruled out as a trigger for pulmonary complications. The absence of an explanatory pathogenic mechanism has led to controversy in clinical practice and the consideration of alternatives [30-35].

Here, we generate the hypothesis that deficient bioavailability of nitric oxide (NO) underlies the increased mortality associated with antiseptic mouthwash use. NO plays a key role in several aspects of human physiology. However, the oral microbiome is disturbed by antiseptic mouthwashes, blunting the nitrate-nitrite-NO pathway and leading to defective NO bioavailability.

\section{The enterosalivary nitrate-nitrite-NO pathway}

A short-lived highly reactive free radical, NO is generated through the classic NO synthase-dependent pathway, or alternatively by the enzyme-independent enterosalivary pathway [36] (Fig. 1). The NO synthasedependent pathway generates $\mathrm{NO}$ from $\mathrm{L}$-arginine, $\mathrm{O}_{2}$, and several co-factors. As this system requires oxygen, it is compromised in the case of local hypoxia. During hypoxia, the alternative enzyme-independent pathway is enhanced, ensuring NO bioavailability. In biological 
fluids, oxygenated haemoglobin rapidly oxidizes NO to nitrate and nitrite. After being taken up by the salivary glands, nitrate is excreted in the saliva. Nitrate is also obtained from the diet, as it is abundant in beetroot and green leafy vegetables. In the oral cavity, facultative anaerobic bacteria residing in crypts on the posterior part of the tongue partially reduce nitrate to nitrite [37]. Nitrite and any remaining nitrate are ingested into the stomach. In the acidity of the gastric milieu, nitrite is non-enzymatically reduced to NO. Subsequently, nitrate and the remaining nitrite pass to the intestines and are systemically absorbed. Nitrite in the circulation can be further reduced to NO following a complex of enzymatic and non-enzymatic pathways, whereas nitrate enters the salivary loop. Essential components of NO production are the active uptake of circulating nitrate and excretion of nitrate in the saliva by the salivary glands, and then the reduction of nitrate to nitrite by the oral flora.
As a considerable proportion of the nitrite in blood and tissues results from dietary consumption, nitrate intake combined with oral bacteria activity on nitrate may offer upfront protection against conditions associated with NO deficiency $[38,39]$. As such, the enterosalivary nitrate-nitrite-NO pathway modulates NO homeostasis and denotes a symbiosis between the oral bacterial flora and the host [40, 41].

\section{Role of NO in biological processes}

In nearly all organs and tissues, NO is involved in a broad spectrum of physiological processes [42]. The positive effects of NO include aspects of the maintenance of vascular tone and permeability, inhibition of platelet aggregation and leucocyte adhesion, protection against antioxidants, neurotransmission, and mitochondrial respiration [43]. In the enzyme-dependent generation of

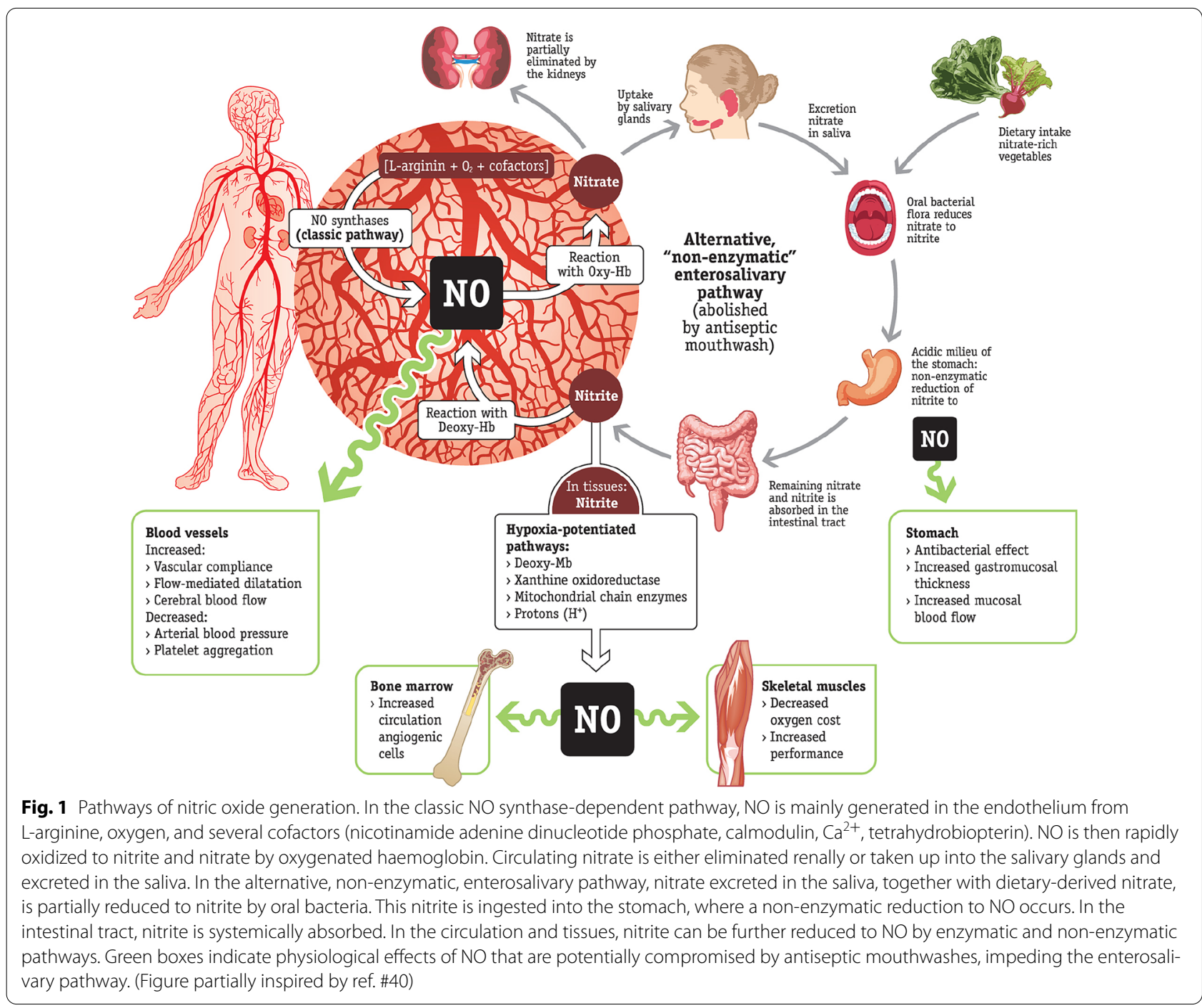


$\mathrm{NO}$, three isoforms of NO synthase have been defined and named based on the cells/tissues where they were initially discovered, but they may be expressed in different cell types. Neuronal NO synthase plays a role in central and peripheral neural signalling. Inducible NO synthase is a key mediator of immune activation and inflammation. It is released in macrophages by bacterial products and diverse cytokines, providing a defence against viruses and bacteria [44]. However, overexpression of inducible NO synthase has deleterious effects. For example, in sepsis, excessive NO concentration is associated with muscle wasting syndrome, acute kidney injury, arterial pulmonary hypertension, pro-apoptotic effects in the liver, and unfavourable haemodynamic consequences, such as a diminished response to vasoconstriction and negative inotropism [42, 45-48]. Thus, NO plays a role in bacterial killing and optimized perfusion, as well as tissue damage, capillary leak, and organ failure [49-51]. Endothelial NO synthase modulates vascular tone and maintains endothelial integrity. NO has a direct vasodilatation effect and is a well-known factor in cardiovascular health. Multiple animal experimental and clinical studies have demonstrated favourable effects associated with nitrate supplementation-based boosting of the enterosalivary nitrate-nitrite-NO pathway, including reduced blood pressure, a cytoprotective effect against myocardial ischaemia-reperfusion injury, reversal of vascular dysfunction in older adults, cardiac protection through restoration of NO homeostasis, improved angiogenesis following chronic ischaemia, and an advantageous influence on cerebral vasospasm in subarachnoid haemorrhage [52-59]. Notably, the favourable cholesterol-independent effects of statins, such as reduced blood pressure, improved angiogenesis, and benefits in patients with heart failure, are realized through increased expression and function of endothelial NO synthases by a variety of mechanisms and pathways [60]. Hou et al. demonstrated that homocysteine-induced endothelial dysfunction, a well-known risk factor in cardiovascular disease, is reversed by enhancing endothelial NO synthase [61]. In the renal microcirculation, NO mediates the vascular tone and tubular function [46]. Furthermore, the non-enzymatically generated NO in the stomach provides host defence against orally ingested microorganisms, and the presence of nitrite in saliva has a positive effect on the integrity of the gastric mucosa by improving mucosal perfusion and mucus thickness [37, 62]. These favourable aspects of NO on human physiological processes have been proposed as therapeutic opportunities for inorganic nitrite [40].

\section{Effects of antiseptic mouthwashes on NO homeostasis and morbidity}

The capacity of oral bacteria to reduce nitrate has been demonstrated in different ways. First, the absence of nitrate reduction has been observed in germ-free rats [37]. Second, antibiotic therapy results in reduced bacterial numbers and blunted salivary nitrate reduction [63]. This was assumed to at least partially be responsible for Salmonella gastroenteritis or oral candidiasis in patients exposed to antibiotic therapy. Third, a series of trials with antiseptic mouthwash have associated blunted nitrate-reduction with increased blood pressure. A $0.12 \%$ chlorhexidine antiseptic mouthwash destroys up to $94 \%$ of the oral bacteria that reduce nitrate and decreases the proportion of reduced nitrate by $85 \%$ (from 17 to $4 \%$ ) [64]. The results of five human crossover studies [65-69] and three controlled animal experiments [54, 70, 71] assessing the effect of antiseptic mouthwashes on blood pressure and the enterosalivary nitrate-nitrite-NO pathway were summarized in a systematic review [72]. Two of the animal studies and all the human studies reported that antiseptic mouthwash had deleterious effects on at least one of the outcome variables (i.e., blood pressure and nitrate/nitrite levels in the saliva or plasma). Three human studies assessed the effects without oral nitrate supplementation to explore the underlying mechanisms [65-67]. Two of these studies found significantly increased systolic blood pressure $(3.5 \mathrm{mmHg}$ and $2 \mathrm{mmHg}$ [ $[65,66]$. Tribble et al. found that a twice daily mouthwash using a $0.12 \%$ chlorhexidine solution for a week significantly increased blood pressure in healthy subjects [73]. A substantial effect was shown, with 13 of 27 study subjects demonstrating an at least $5 \mathrm{mmHg}$ increase in systolic blood pressure at rest. Salvage from mouthwash use showed enhancement of the oral bacteria capable of reducing nitrate. Finally, Bescos et al. demonstrated that chlorhexidine mouthwashes for 7 days led to a major shift in salivary microbiome resulting in more acidic conditions, lower nitrite availability and higher systolic blood pressure in healthy study subjects [74].

Epidemiological studies have also found a relationship between antiseptic mouthwash use and cardiovascular health. In a cohort of middle-aged (40-65 years) overweight or obese individuals, Joshipura et al. evaluated the risk of hypertension developing over 3 years [75]. Twelve percent of 540 individuals developed hypertension. The risk of hypertension was higher in individuals using an antiseptic mouthwash at least twice daily than in less frequent users [incidence rate ratio (IRR) 1.85, 95\% CI 1.17-2.94] and non-mouthwash users (IRR 2.17, 95\% CI 1.27-3.71). These associations were independent of the major risk factors associated with hypertension, including dietary habits and smoking. Using a similar approach 
in the same cohort, they found that the risk of developing pre-diabetes/diabetes was higher in individuals using an antiseptic mouthwash at least twice daily than less frequent users (IRR 1.55, 95\% CI 1.21-1.99) and nonmouthwash users (IRR 1.49, 95\% CI 1.13-1.95) [76].

\section{Pathologies associated with deficient NO bioavailability}

The above-mentioned studies underscore a relationship between compromised oral bacterial flora and cardiovascular and endocrine morbidity. This relationship can be attributed to a disturbance in the enterosalivary nitrate-nitrite-NO pathway, resulting in decreased NO bioavailability. The importance of NO for human health is stressed by multiple examples of pathologies that are induced or worsened by insufficient bioavailability of NO.

\section{Cardiovascular}

Reduced activation of endothelial NO synthase was associated with cardiac hypertrophy, fibrosis, increased natriuretic peptide levels, and oxidative stress in an animal model of chronic kidney injury [77]. These alterations were prevented by the administration of L-arginine, an essential component of NO synthase-dependent $\mathrm{NO}$ generation. Endothelial NO synthase concentrations are also significantly lower in patients with unstable angina pectoris compared to controls, leading to the idea that NO may serve as a biomarker to predict coronary lesion severity and complexity [78]. Furthermore, in patients receiving coronary artery bypass grafts, NO concentrations were significantly lower among those developing postoperative hypertension [79]. Interestingly, when sodium nitroprusside was started, NO concentrations increased and catecholamine levels decreased. Reduced NO concentrations also contribute to endothelial dysfunction, an important event in atherosclerotic development $[80,81]$. Actually, defective NO function in the endothelium is associated with all foremost cardiovascular risk factors including hypertension, hyperlipidaemia, smoking, diabetes mellitus, and severity of established atherosclerosis [58].

\section{Endocrine}

Reduced NO bioavailability affects endocrine health via enhanced insulin resistance and obesity. Low NO bioavailability is assumed to directly lead to insulin resistance due to disturbed lipid control, increased fat mass, and decreased glucose delivery [82-84]. Obese patients have improved insulin sensitivity following nitrate supplementation by beetroot juice intake [85]. However, this favourable effect is erased following antiseptic mouthwash. These effects have not been observed in healthy nonobese adults, stressing the possibility that obese patients are more prone to NO depletion when exposed to antiseptic mouthwash. Of note, Carlström et al. demonstrated that mice, at risk for metabolic syndrome because of their endothelial NO synthase-deficient status, experienced reversed features of metabolic syndrome following a nitrate-rich dietary intake (i.e., reduction in weight and visceral fat, and lower levels of circulating triglycerides) [86].

\section{Wound healing}

Because of its role in angiogenesis, endothelial homeostasis, and inflammation, $\mathrm{NO}$ is also important in wound healing. Reduced collagen deposition and tensile strength, and delayed wound re-epithelialization have been demonstrated in mice under NO-free conditions [87]. Moreover, disease states characterized by a deficiency in NO, including diabetes mellitus and malnutrition, as well as corticosteroid use, are associated with poor wound healing [88-92]. Suboptimal wound healing facilitates wound infection and sepsis.

\section{Sepsis}

NO plays a protective role in sepsis via better organ perfusion through microcirculatory vasodilation. In early sepsis, NO likely contributes to microbial clearance through NO-derived mediators with antibacterial capabilities [93]. Multiple experimental and clinical studies have stressed the association between decreased NO bioavailability and sepsis susceptibility, severity, and outcomes. The immune dysfunction seen late after burn injury results in decreased NO production, which may lead to increased susceptibility to sepsis in burn patients [94]. Several clinical studies have found associations between reduced NO bioavailability and sepsis severity. NO has a short half-life in plasma and is a challenge to measure; therefore, trials often use proxies of NO bioavailability. Using such approaches relationships between deficient bioavailability and the occurrence of sepsis has been demonstrated [95]. Furthermore, among septic patients, reduced bioavailability of $\mathrm{NO}$ is associated with greater endothelial activity and capillary leakage [96], more severe organ failure, and mortality [97-99]. However, these observations rely on a deficient endothelial NO synthase pathway. The relevance of the enzyme-independent pathway in circulatory and septic shock is demonstrated by Cauwels and colleagues [100]. In a mouse model, they demonstrated the protective effect of intravenous pretreatment with sodium nitrite against hypothermia and mortality following a lethal dose of tumor necrosis factor and Gram-negative lipopolysaccharide. Therapeutic treatment with nitrite provided additional protection if administered when hypothermia was not yet too severe. These experiments suggest that circulating 
nitrite is an important source of NO in hypoxic/ischaemic conditions and may give occasion to the development of treatment options for sepsis [101, 102].

\section{Can a disturbance in the nitrate-nitrite-NO pathway by antiseptic mouthwash lead to increased mortality in hospitalized patients?}

The previous data clearly indicate the important role of $\mathrm{NO}$ in physiology, the important role of the enterosalivary nitrate-nitrite-NO pathway in NO homeostasis, that reduced NO bioavailability is associated with the occurrence or worsening of pathophysiological processes, and that this pathway is diminished by the use of antiseptic mouthwash. Whether antiseptic mouthwashes cause excess mortality is unclear. However, at least two types of potentially fatal events may be facilitated by deficient $\mathrm{NO}$ bioavailability provoked by antiseptic mouthwashes.

\section{Ischaemic cardiovascular events}

Several controlled trials have demonstrated increased arterial blood pressure in subjects exposed to antiseptic mouthwash [65, 66, 73]. Though the absolute increase in systolic blood pressure was rather small $(2-5 \mathrm{mmHg})$, even a $2 \mathrm{mmHg}$ increase corresponds with an increased risk of mortality from stroke of $10 \%$ or from ischaemic heart disease of $7 \%$ in middle-aged patients [103]. All these mouthwash-controlled studies were executed in healthy volunteers or, at most, in patients with comorbidities under stable conditions (i.e., treated hypertension). However, the NO homeostasis may be more easily disturbed in patients whose clinical status is compromised by recent surgery, acute illness, or exacerbation of chronic underlying conditions than in healthy individuals. Multiple health risk factors, including obesity, hyperlipidaemia, and hypertension, contribute to atherosclerosis, a condition leading to local tissue hypoxia. However, as the NO synthase-based pathway is oxygendependent, NO generation is mainly dependent on the non-enzymatic and oxygen-independent enterosalivary pathway, which is compromised by antiseptic mouthwash. This is illustrated by a case report of a patient with angina pectoris whose symptoms resolved following cessation of twice daily antiseptic mouthwash use [104].

\section{Septic events}

Reduced NO bioavailability facilitating infection and sepsis is supported by the multicentre ICU cohort reported by Parreco et al. [21]. After excluding patients with a diagnosis of sepsis at admission, the overall rate of sepsis among patients exposed to chlorhexidine mouthwash was $3.3 \%$ compared to $1.8 \%$ in unexposed patients $(p<0.001)$. Chlorhexidine mouthwash remained an independent risk factor for sepsis after controlling for confounders (OR 1.37, 95\% CI 1.19-1.59).

\section{Discussion}

The observed risk of mortality associated with antiseptic mouthwash use is hypothesized to be caused by an obliteration of the oral bacterial flora, resulting in a disturbance in the enterosalivary nitrate-nitrite-NO pathway. This condition leads to defective NO bioavailability, facilitating the occurrence of cardiovascular and septic events.

However, several issues need to be considered. First, thus far, the link between antiseptic mouthwashes and increased mortality has been observed exclusively with chlorhexidine-based mouthwashes [16-18, 20, 21]. However, based on the outlined hypothesis, the potentially deleterious effect cannot be limited to a particular mouthwash. Potentially every mouthwash with antiseptic properties against nitrate-reducing oral bacteria should be capable of decreasing the NO bioavailability and provoking adverse events. Chlorhexidine, however, is used for a plethora of applications, particularly because of its sustained effect, an unfavourable quality pertaining to a healthy oral microbiome [105]. Little is known about the impact of distinct antiseptic mouthwash solutions on the nitrate-nitrite-NO pathway. In an experimental setting, Woesner et al. reported significantly higher systolic blood pressures following chlorhexidine $0.12 \%$ and cetylpyridinium $0.05 \%$ mouthwash solutions compared with controls or study subjects exposed to Listerine mouthwashes [69]. However, to the best of our knowlegde, no effect of different oral care solutions on nitrate-reducing oral flora are reported. Second, though a recent meta-analysis confirmed the role of oral bacteria in salivary nitrate metabolism, their influence on plasma NO bioavailability requires confirmation [106].

Third, in addition to mouthwashes, several other agents can disrupt the nitrate-nitrite-NO pathway, such as smoking, antibiotics, high concentrations of ascorbate, and proton-pump inhibitors [107]. Concerning the latter, Montenegro et al. demonstrated in a randomized, double-blind, placebo-controlled, cross-over study in healthy subjects that the blood pressure lowering effect of oral nitrite ingestion remains absent when pretreated with esomeprazole [108]. A similar observation was made in an experimental setting with rats [109]. Based on these observations, one may assume that in patients treated with proton-pump inhibitors antiseptic mouthwashes may not have an additional adverse effect. Concerning antibiotics, while the negative impact of amoxicillin on salivary nitrite has been demonstrated, [63] subsequent enterosalivary pathway-derived adverse events following 
antibiotic exposure remain unexplored. Of note, antibiotic indications (i.e., infection or risk of infection) constitutes an inherent bias in the attempt to answer the research question. Selective oral decontamination could also harm the nitrate-reducing oral flora. However, such a prophylactic approach did not increase mortality in a large trial [110]. It can be assumed that the high baseline mortality in this study (27.5\% of 28 -day mortality) is responsible for the absence of harm. One may indeed question why chlorhexidine mouthwashes are not associated with mortality in patients with a particularly grim prognosis. In a large randomized-controlled trial in ventilated patients Wittekamp et al. reported hospital mortality rates in patients receiving baseline care (chlorhexidine mouthwash at standard concentrations, i.e. $0.12 \%$ or $0.2 \%$, in 11 out of 13 units), chlorhexidine mouthwash at high concentrations ( $2 \%$ replaced by $1 \%$ solution [26]), selective oral decontamination, and selective digestive decontamination [111]. Mortality ranged $38-40.3 \%$ and was not different between the study groups. Likewise, in the large hospital-wide cohort by Deschepper et al., [20] the association between chlorhexidine mouthwash and death was absent in patients with an inherently extreme mortality risk based on the All Patient Refined-Diagnosis Related Groups (OR 1.13, 95\% CI 0.9-1.41), but present in patients with a more favorable prognosis [112]. Being exposed to chlorhexidine mouthwash was significantly associated with death in patients with a minor/moderate risk of mortality (OR 5.5, 95\% CI 4.51-6.71) and patients with a major risk of mortality (OR 2.33, 95\% CI 1.962.78). The overall observed mortality in the latter groups was $0.8 \%$ and $10.9 \%$, respectively, while it was $41.9 \%$ in the group with an extreme risk of mortality. Analogously, the overall mortality in the ICU cohort described by Parreco et al., who found excess mortality associated with chlorhexidine mouthwashes, was $6.9 \%$, considerably lower than the mortality reported by Wittekamp et al. (38.1\%) and the extreme risk subgroup reported by Deschepper et al. (41.9\%) [20, 21, 111]. At the same line, a recent meta-analysis of 11 studies on critically ill patients ventilated at least $48 \mathrm{~h}$, with a high $24 \%$ baseline mortality among the control groups, did not find excess mortality in patients exposed to chlorhexidine mouthwash [113]. This observation could be due to a greater contribution of complications to mortality in moderately ill patients than in critically ill patients. Among critically ill patients, a greater proportion of the mortality is attributed to the general disease severity, as observed in studies assessing the impact of infectious complications [114-117].

Finally, ideally, this hypothesis should be tested by a hospital-wide randomized-controlled trial comparing antiseptic mouthwash exposed with non-exposed patients. Hereby surrogates of NO bioavailability should be monitored, linked with the occurrence rate of septic and ischaemic heart events, and subsequent mortality. However, the association between antiseptic mouthwash and mortality constitutes a rare event that could only be verified in large cohorts and meta-analyses. In the study by Deschepper et al. including 82,274 patients $(11,133$ exposed), the number of patients that need to be exposed to add 1 additional fatality was 47 (95\% CI 45-49), compromising the achievement of a sufficiently powered randomized controlled trial [20]. In a hospital-wide population with $2 \%$ baseline mortality, a trial must include 42,216 patients to be able to demonstrate a $20 \%$ difference in mortality (alpha $=0.05$, power $=0.8$ ). Large prospective cohort studies with detailed data collection seem more realistic. Thus, special emphasis should be given to antiseptic mouthwash exposure (product, concentration, frequency, and duration of use), other agents compromising the oral microbiome (smoking habits, antibiotics, proton-pump inhibitors), aspects of severity of acute illness (e.g., acute organ failure), patients' comorbidities (especially cardiovascular risk factors, e.g., atherosclerosis, hypertension, and obesity), and adverse events complicating the hospital course, especially ischaemic heart events and septic complications. To further explore the link between the oral microbiome and harm, monitoring the oral flora with use of metataxonomic analysis may be carry out in a randomly selected proportion of patients. In these patients, salivary and circulating nitrite concentrations, as well as surrogate markers of bioavailability of NO could be measured. However, such in-depth analyses will add to the complexity of the trial.

In conclusion, we generated the hypothesis that a disturbance of the nitrate-nitrite-NO pathway by oral antiseptics may be the pathogenic mechanism behind the observed relationship with mortality. While this hypothesis remains unproven, based on the available meta-analyses and observational cohort studies, it is recommended to restrict the use of oral antiseptics to indications supported by evidence.

\section{Author details \\ ${ }^{1}$ Department of Internal Medicine and Pediatrics, Faculty of Medicine and Health Sciences, Ghent University, Campus UZ Gent, Corneel Heyman- slaan 10, 9000 Ghent, Belgium. ${ }^{2}$ Burns, Trauma, and Critical Care Research Centre, Faculty of Medicine, The University of Queensland, Brisbane, Australia.}

\section{Acknowledgements}

Special thanks to Mr. Hugues Meert, graphic designer at Creative Solutions (Ghent, Belgium), for lifting the figure to a professional level.

Compliance with ethical standards

Conflicts of interest

The authors declare that they have no conflict of interest. 


\section{Publisher's Note}

Springer Nature remains neutral with regard to jurisdictional claims in published maps and institutional affiliations.

Received: 10 August 2020 Accepted: 3 October 2020

Published online: 16 October 2020

\section{References}

1. Seymour GJ (2007) You cannot have good general health without good oral health. N Z Dent J 103:26-27

2. Chadwick B, White D, Lader D, Pitts N (2011) Preventive behaviour and risks to oral health - a report from the Adult Dental Health Survey 2009. NHS Information Centre for Health and Social Care, London

3. Preshaw PM (2018) Mouthwash use and risk of diabetes. Br Dent J 225:923-926. https://doi.org/10.1038/sj.bdj.2018.1020

4. Seymour GJ, Ford PJ, Cullinan MP et al (2007) Relationship between periodontal infections and systemic disease. Clin Microbiol Infect 13(Suppl 4):3-10. https://doi.org/10.1111/j.1469-0691.2007.01798.x

5. Maeda K, Mori N (2020) Poor oral health and mortality in geriatric patients admitted to an acute hospital: an observational study. BMC Geriatr 20:26-27. https://doi.org/10.1186/s12877-020-1429-z

6. Hollaar V, van der Maarel-Wierink C, van der Putten G-J et al (2015) Effect of daily application of a $0.05 \%$ chlorhexidine solution on the incidence of (aspiration) pneumonia in care home residents: design of a multicentre cluster randomised controlled clinical trial. BMJ Open 5:e007889. https://doi.org/10.1136/bmjopen-2015-007889

7. Sharif-Abdullah SSB, Chong MC, Surindar-Kaur SS et al (2016) The effect of chlorhexidine in reducing oral colonisation in geriatric patients: a randomised controlled trial. Singap Med J 57:262-266. https://doi. org/10.11622/smedj.2016091

8. Juthani-Mehta M, Van Ness PH, McGloin J et al (2015) A cluster-randomized controlled trial of a multicomponent intervention protocol for pneumonia prevention among nursing home elders. Clin Infect Dis 60:849-857. https://doi.org/10.1093/cid/ciu935

9. De Siena F, Francetti L, Corbella S et al (2013) Topical application of $1 \%$ chlorhexidine gel versus $0.2 \%$ mouthwash in the treatment of periimplant mucositis. An observational study. Int J Dent Hyg 11:41-47. https://doi.org/10.1111/idh.12002

10. da Costa LFNP, Amaral CDSF, Barbirato DDS et al (2017) Chlorhexidine mouthwash as an adjunct to mechanical therapy in chronic periodontitis: A meta-analysis. J Am Dent Assoc 148:308-318. https://doi. org/10.1016/j.adaj.2017.01.021

11. Genovesi A, Barone A, Toti P, Covani U (2017) The efficacy of $0.12 \%$ chlorhexidine versus $0.12 \%$ chlorhexidine plus hyaluronic acid mouthwash on healing of submerged single implant insertion areas: a short-term randomized controlled clinical trial. Int J Dent Hyg 15:65-72. https://doi. org/10.1111/idh.12158

12. Labeau SO, Van de Vyver K, Brusselaers N et al (2011) Prevention of ventilator-associated pneumonia with oral antiseptics: a systematic review and meta-analysis. Lancet Infect Dis 11:845-854. https://doi. org/10.1016/S1473-3099(11)70127-X

13. American Thoracic Society, Infectious Diseases Society of America (2005) Guidelines for the management of adults with hospitalacquired, ventilator-associated, and healthcare-associated pneumonia. Am J Respir Crit Care Med 171:388-416. https://doi.org/10.1164/ rccm.200405-644ST

14. Healthcare Infection Control Practices Advisory Committee, Centers for Disease Control and Prevention (U.S.) (2004) Guidelines for preventing health-care-associated pneumonia, 2003 recommendations of the CDC and the Healthcare Infection Control Practices Advisory Committee. Respir Care 49:926-939

15. Institute for Healthcare Improvement (2012) How-to guide: prevent ventilator-associated pneumonia. Institute for Healthcare Improvement, Cambridge

16. Klompas M, Speck K, Howell MD et al (2014) Reappraisal of routine oral care with chlorhexidine gluconate for patients receiving mechanical ventilation: systematic review and meta-analysis.
JAMA Intern Med 174:751-761. https://doi.org/10.1001/jamaintern med.2014.359

17. Price R, MacLennan G, Glen J, Collaboration SuDDICU (2014) Selective digestive or oropharyngeal decontamination and topical oropharyngeal chlorhexidine for prevention of death in general intensive care: systematic review and network meta-analysis. BMJ 348:g2197-g2197. https://doi.org/10.1136/bmj.g2197

18. Klompas M, Li L, Kleinman K et al (2016) Associations between ventilator bundle components and outcomes. JAMA Intern Med 176:1277-1283. https://doi.org/10.1001/jamainternmed.2016.2427

19. Torres A, Niederman MS, Chastre J et al (2017) International ERS/ ESICM/ESCMID/ALAT guidelines for the management of hospitalacquired pneumonia and ventilator-associated pneumonia: Guidelines for the management of hospital-acquired pneumonia (HAP)/ ventilator-associated pneumonia (VAP) of the European Respiratory Society (ERS), European Society of Intensive Care Medicine (ESICM), European Society of Clinical Microbiology and Infectious Diseases (ESCMID) and Asociación Latinoamericana del Tórax (ALAT). Eur Respir J 50:1700582. https://doi.org/10.1183/13993003.00582-2017

20. Deschepper M, Waegeman W, Eeckloo K et al (2018) Effects of chlorhexidine gluconate oral care on hospital mortality: a hospital-wide, observational cohort study. Intensive Care Med 44:1017-1026. https //doi.org/10.1007/s00134-018-5171-3

21. Parreco J, Soe-Lin H, Byerly S et al (2020) Multi-center outcomes of chlorhexidine oral decontamination in intensive care units. Surg Infect (Larchmt). https://doi.org/10.1089/sur.2019.172

22. Okano M, Nomura M, Hata S et al (1989) Anaphylactic symptoms due to chlorhexidine gluconate. Arch Dermatol 125:50-52

23. Jee R, Nel L, Gnanakumaran G et al (2009) Four cases of anaphylaxis to chlorhexidine impregnated central venous catheters: a case cluster or the tip of the iceberg? Br J Anaesth 103:614-615. https://doi. org/10.1093/bja/aep248

24. Stephens R, Mythen M, Kallis P et al (2001) Two episodes of lifethreatening anaphylaxis in the same patient to a chlorhexidine-sulphadiazine-coated central venous catheter. Br J Anaesth 87:306-308

25. Parkes AW, Harper N, Herwadkar A, Pumphrey R (2009) Anaphylaxis to the chlorhexidine component of Instillagel: a case series. $\mathrm{Br} J$ Anaesth 102:65-68. https://doi.org/10.1093/bja/aen324

26. Plantinga NL, Wittekamp BHJ, Leleu K et al (2016) Oral mucosal adverse events with chlorhexidine $2 \%$ mouthwash in ICU. Intensive Care Med 42:620-621. https://doi.org/10.1007/s00134-016-4217-7

27. Bellissimo-Rodrigues WT, Menequeti MG, de Macedo LD et al (2019) Oral mucositis as a pathway for fatal outcome among critically ill patients exposed to chlorhexidine: post hoc analysis of a randomized clinical trial. Crit Care 23:382-383. https://doi.org/10.1186/s1305 4-019-2664-6

28. Xue Y, Zhang S, Yang $Y$ et al (2011) Acute pulmonary toxic effects of chlorhexidine (CHX) following an intratracheal instillation in rats. Hum Exp Toxicol 30:1795-1803. https://doi.org/10.1177/0960327111 400104

29. Hirata K, Kurokawa A (2002) Chlorhexidine gluconate ingestion resulting in fatal respiratory distress syndrome. Vet Hum Toxicol 44:89-91

30. Ricard JD, Lisboa T (2018) Caution for chlorhexidine gluconate use for oral care: insufficient data. Intensive Care Med 11:845-853. https://doi. org/10.1007/s00134-018-5217-6

31. Bouadma L, Karpanen T, Elliott T (2018) Chlorhexidine use in adult patients on ICU. Intensive Care Med 30:827-833. https://doi. org/10.1007/s00134-018-5137-5

32. Bouadma L, Klompas M (2018) Oral care with chlorhexidine: beware! Intensive Care Med 35:915-923. https://doi.org/10.1007/s0013 4-018-5221-x

33. Dale CM, Rose L, Carbone S et al (2019) Protocol for a multi-centered, stepped wedge, cluster randomized controlled trial of the deadoption of oral chlorhexidine prophylaxis and implementation of an oral care bundle for mechanically ventilated critically ill patients: the CHORAL study. Trials 20:603-608. https://doi.org/10.1186/s1306 3-019-3673-0

34. Klarin B, Adolfsson A, Torstensson A, Larsson A (2018) Can probiotics be an alternative to chlorhexidine for oral care in the mechanically ventilated patient? A multicentre, prospective, randomised 
controlled open trial. Crit Care 22:272-310. https://doi.org/10.1186/ s13054-018-2209-4

35. Hamilton LA, Behal ML (2020) Altering routine intensive care unit practices to support commensalism. Nutr Clin Pract 35:433-441. https://doi. org/10.1002/ncp.10484

36. Hezel MP, Weitzberg E (2015) The oral microbiome and nitric oxide homoeostasis. Oral Dis 21:7-16. https://doi.org/10.1111/odi.12157

37. Duncan C, Dougall H, Johnston P et al (1995) Chemical generation of nitric oxide in the mouth from the enterosalivary circulation of dietary nitrate. Nat Med 1:546-551. https://doi.org/10.1038/nm0695-546

38. Bryan NS, Fernandez BO, Bauer SM et al (2005) Nitrite is a signaling molecule and regulator of gene expression in mammalian tissues. Nat Chem Biol 1:290-297. https://doi.org/10.1038/nchembio734

39. Bryan NS (2006) Nitrite in nitric oxide biology: cause or consequence? A systems-based review. Free Radic Biol Med 41:691-701. https://doi. org/10.1016/j.freeradbiomed.2006.05.019

40. Lundberg JO, Weitzberg E, Gladwin MT (2008) The nitrate-nitrite-nitric oxide pathway in physiology and therapeutics. Nat Rev Drug Discov 7:156-167. https://doi.org/10.1038/nrd2466

41. Lundberg JO, Weitzberg E, Cole JA, Benjamin N (2004) Nitrate, bacteria and human health. Nat Rev Microbiol 2:593-602. https://doi. org/10.1038/nrmicro929

42. Carnovale CE, Ronco MT (2012) Role of nitric oxide in liver regeneration. Ann Hepatol 11:636-647

43. Hollenberg SM, Cinel I (2009) Bench-to-bedside review: nitric oxide in critical illness-update 2008. Crit Care 13:218-219. https://doi. org/10.1186/cc7706

44. Fang FC (2004) Antimicrobial reactive oxygen and nitrogen species: concepts and controversies. Nat Rev Microbiol 2:820-832. https://doi. org/10.1038/nrmicro1004

45. Hall DT, Ma JF, Marco SD, Gallouzi I-E (2011) Inducible nitric oxide synthase (iNOS) in muscle wasting syndrome, sarcopenia, and cachexia. Aging (Albany NY) 3:702-715. https://doi.org/10.18632/aging.100358

46. Aksu U, Demirci C, Ince C (2011) The pathogenesis of acute kidney injury and the toxic triangle of oxygen, reactive oxygen species and nitric oxide. Contrib Nephrol 174:119-128. https://doi. org/10.1159/000329249

47. Boehm M, Novoyatleva T, Kojonazarov B et al (2019) Nitric oxide synthase 2 induction promotes right ventricular fibrosis. Am J Respir Cell Mol Biol 60:346-356. https://doi.org/10.1165/rcmb.2018-00690C

48. Vincent JL, Zhang H, Szabo C, Preiser JC (2000) Effects of nitric oxide in septic shock. Am J Respir Crit Care Med 161:1781-1785. https://doi. org/10.1164/ajrccm.161.6.9812004

49. Rosen H, Crowley JR, Heinecke JW (2002) Human neutrophils use the myeloperoxidase-hydrogen peroxide-chloride system to chlorinate but not nitrate bacterial proteins during phagocytosis. J Biol Chem 277:30463-30468. https://doi.org/10.1074/jbc.M202331200

50. Goya T, Morisaki T, Torisu M (1994) Immunologic assessment of host defense impairment in patients with septic multiple organ failure: relationship between complement activation and changes in neutrophil function. Surgery 115:145-155

51. Linares E, Giorgio S, Mortara RA et al (2001) Role of peroxynitrite in macrophage microbicidal mechanisms in vivo revealed by protein nitration and hydroxylation. Free Radic Biol Med 30:1234-1242. https:// doi.org/10.1016/s0891-5849(01)00516-0

52. Bryan NS, Calvert JW, Elrod JW et al (2007) Dietary nitrite supplementation protects against myocardial ischemia-reperfusion injury. Proc Natl Acad Sci USA 104:19144-19149. https://doi.org/10.1073/pnas.07065 79104

53. Bryan NS, Ivy JL (2015) Inorganic nitrite and nitrate: evidence to support consideration as dietary nutrients. Nutr Res 35:643-654. https://doi. org/10.1016/j.nutres.2015.06.001

54. Petersson J, Carlström M, Schreiber O et al (2009) Gastroprotective and blood pressure lowering effects of dietary nitrate are abolished by an antiseptic mouthwash. Free Radic Biol Med 46:1068-1075. https://doi. org/10.1016/j.freeradbiomed.2009.01.011

55. Larsen FJ, Ekblom B, Sahlin K et al (2006) Effects of dietary nitrate on blood pressure in healthy volunteers. N Engl J Med 355:2792-2793. https://doi.org/10.1056/NEJMc062800

56. Webb A, Bond R, McLean P et al (2004) Reduction of nitrite to nitric oxide during ischemia protects against myocardial ischemia-reperfusion damage. Proc Natl Acad Sci USA 101:1368313688. https://doi.org/10.1073/pnas.0402927101

57. Duranski MR, Greer JJM, Dejam A et al (2005) Cytoprotective effects of nitrite during in vivo ischemia-reperfusion of the heart and liver. J Clin Invest 115:1232-1240. https://doi.org/10.1172/JCI22493

58. Bryan NS, Tribble G, Angelov N (2017) Oral microbiome and nitric oxide: the missing link in the management of blood pressure. Curr Hypertens Rep 19:33. https://doi.org/10.1007/s11906-017-0725-2

59. Hendgen-Cotta UB, Luedike $P$, Totzeck M et al (2012) Dietary nitrate supplementation improves revascularization in chronic ischemia. Circulation 126:1983-1992. https://doi.org/10.1161/CIRCULATIO NAHA. 112.112912

60. Gorabi AM, Kiaie N, Hajighasemi S et al (2019) Statin-induced nitric oxide signaling: mechanisms and therapeutic implications. J Clin Med 8:2051. https://doi.org/10.3390/jcm8122051

61. Hou H-T, Wang J, Zhang X et al (2018) Endothelial nitric oxide synthase enhancer AVE3085 reverses endothelial dysfunction induced by homocysteine in human internal mammary arteries. Nitric Oxide 81:21-27. https://doi.org/10.1016/j.niox.2018.10.001

62. Björne HH, Petersson J, Phillipson M et al (2004) Nitrite in saliva increases gastric mucosal blood flow and mucus thickness. J Clin Invest 113:106-114. https://doi.org/10.1172/JCl19019

63. Dougall HT, Smith L, Duncan C, Benjamin N (1995) The effect of amoxycillin on salivary nitrite concentrations: an important mechanism of adverse reactions? Br J Clin Pharmacol 39:460-462. https://doi. org/10.1111/j.1365-2125.1995.tb04479.x

64. Shapiro KB, Hotchkiss JH, Roe DA (1991) Quantitative relationship between oral nitrate-reducing activity and the endogenous formation of N-nitrosoamino acids in humans. Food Chem Toxicol 29:751-755. https://doi.org/10.1016/0278-6915(91)90183-8

65. Kapil V, Haydar SMA, Pearl V et al (2013) Physiological role for nitratereducing oral bacteria in blood pressure control. Free Radic Biol Med 55:93-100. https://doi.org/10.1016/j.freeradbiomed.2012.11.013

66. Bondonno CP, Liu AH, Croft KD et al (2015) Antibacterial mouthwash blunts oral nitrate reduction and increases blood pressure in treated hypertensive men and women. Am J Hypertens 28:572-575. https:// doi.org/10.1093/ajh/hpu192

67. Sundqvist ML, Lundberg JO, Weitzberg E (2016) Effects of antiseptic mouthwash on resting metabolic rate: a randomized, double-blind, crossover study. Nitric Oxide 61:38-44. https://doi.org/10.1016/j. niox.2016.10.003

68. McDonagh STJ, Wylie LJ, Winyard PG et al (2015) The effects of chronic nitrate supplementation and the use of strong and weak antibacterial agents on plasma nitrite concentration and exercise blood pressure. Int J Sports Med 36:1177-1185. https://doi.org/10.1055/s-0035-1554700

69. Woessner M, Smoliga JM, Tarzia B et al (2016) A stepwise reduction in plasma and salivary nitrite with increasing strengths of mouthwash following a dietary nitrate load. Nitric Oxide 54:1-7. https://doi. org/10.1016/j.niox.2016.01.002

70. Hyde ER, Luk B, Cron S et al (2014) Characterization of the rat oral microbiome and the effects of dietary nitrate. Free Radic Biol Med 77:249-257. https://doi.org/10.1016/j.freeradbiomed.2014.09.017

71. Pinheiro LC, Ferreira GC, Amaral JH et al (2016) Oral nitrite circumvents antiseptic mouthwash-induced disruption of enterosalivary circuit of nitrate and promotes nitrosation and blood pressure lowering effect. Free Radic Biol Med 101:226-235. https://doi.org/10.1016/j.freeradbio med.2016.10.013

72. Senkus KE, Crowe-White KM (2019) Influence of mouth rinse use on the enterosalivary pathway and blood pressure regulation: a systematic review. Crit Rev Food Sci Nutr 28:1-13. https://doi. org/10.1080/10408398.2019.1665495

73. Tribble GD, Angelov N, Weltman R et al (2019) Frequency of tongue cleaning impacts the human tongue microbiome composition and enterosalivary circulation of nitrate. Front Cell Infect Microbiol 9:39. https://doi.org/10.3389/fcimb.2019.00039

74. Bescos R, Ashworth A, Cutler C et al (2020) Effects of chlorhexidine mouthwash on the oral microbiome. Sci Rep 10:5254-5258. https:// doi.org/10.1038/s41598-020-61912-4

75. Joshipura K, Muñoz-Torres F, Fernández-Santiago J et al (2019) Overthe-counter mouthwash use, nitric oxide and hypertension risk. Blood Press 7:1-10. https://doi.org/10.1080/08037051.2019.1680270 
76. Joshipura KJ, Muñoz-Torres FJ, Morou-Bermudez E, Patel RP (2017) Over-the-counter mouthwash use and risk of pre-diabetes/diabetes. Nitric Oxide 71:14-20. https://doi.org/10.1016/j.niox.2017.09.004

77. Amador-Martínez I, Pérez-Villalva R, Uribe N et al (2019) Reduced endothelial nitric oxide synthase activation contributes to cardiovascular injury during chronic kidney disease progression. Am J Physiol Renal Physiol 317:F275-F285. https://doi.org/10.1152/ajprenal.00020 2019

78. Acara AC, Bolatkale M (2019) Endothelial nitric oxide level as a predictor of coronary complexity in patients with unstable angina pectoris. Am J Med Sci 357:453-460. https://doi.org/10.1016/j.amjms .2019.02.011

79. Aydin S (2018) Renalase, catecholamine and nitric oxide changes before and after sodium nitroprusside administration to patients who develop post-coronary artery by-pass (CABG) hypertension. Heart Surg Forum 21:E330-E336. https://doi.org/10.1532/hsf.1998

80. Tousoulis D, Koutsogiannis M, Papageorgiou N et al (2010) Endothelial dysfunction: potential clinical implications. Minerva Med 101:271-284

81. Papageorgiou N, Androulakis E, Papaioannou S et al (2015) Homoarginine in the shadow of asymmetric dimethylarginine: from nitric oxide to cardiovascular disease. Amino Acids 47:1741-1750. https://doi. org/10.1007/s00726-015-2017-y

82. Sansbury BE, Hill BG (2014) Regulation of obesity and insulin resistance by nitric oxide. Free Radic Biol Med 73:383-399. https://doi. org/10.1016/j.freeradbiomed.2014.05.016

83. Gruber H-J, Mayer C, Mangge $\mathrm{H}$ et al (2008) Obesity reduces the bioavailability of nitric oxide in juveniles. Int J Obes (Lond) 32:826-831. https://doi.org/10.1038/sj.ijo.0803795

84. Jankovic A, Korac A, Buzadzic B et al (2017) Targeting the NO/superoxide ratio in adipose tissue: relevance to obesity and diabetes management. Br J Pharmacol 174:1570-1590. https://doi.org/10.1111/ bph.13498

85. Beals JW, Binns SE, Davis JL et al (2017) Concurrent beet juice and carbohydrate ingestion: influence on glucose tolerance in obese and nonobese adults. J Nutr Metab 2017:6436783-6436787. https://doi. org/10.1155/2017/6436783

86. Carlström M, Larsen FJ, Nyström T et al (2010) Dietary inorganic nitrate reverses features of metabolic syndrome in endothelial nitric oxide synthase-deficient mice. Proc Natl Acad Sci USA 107:17716-17720. https://doi.org/10.1073/pnas.1008872107

87. Yamasaki K, Edington HD, McClosky C et al (1998) Reversal of impaired wound repair in iNOS-deficient mice by topical adenoviral-mediated iNOS gene transfer. J Clin Invest 101:967-971. https://doi.org/10.1172/ JCI2067

88. Krausz A, Friedman AJ (2015) Nitric oxide as a surgical adjuvant. Future Sci OA 1:FSO56. https://doi.org/10.4155/fso.15.56

89. Witte MB, Kiyama T, Barbul A (2002) Nitric oxide enhances experimental wound healing in diabetes. Br J Surg 89:1594-1601. https://doi.org/10.1 046/j.1365-2168.2002.02263.x

90. Witte MB, Barbul A (2002) Role of nitric oxide in wound repair. Am J Surg 183:406-412. https://doi.org/10.1016/s0002-9610(02)00815-2

91. Engelen MPKJ, Klimberg VS, Allasia A, Deutz NEP (2018) Major surgery diminishes systemic arginine availability and suppresses nitric oxide response to feeding in patients with early stage breast cancer. Clin Nutr 37:1645-1653. https://doi.org/10.1016/j.clnu.2017.07.019

92. Luiking YC, Ten Have GAM, Wolfe RR, Deutz NEP (2012) Arginine de novo and nitric oxide production in disease states. Am J Physiol Endocrinol Metab 303:E1177-E1189. https://doi.org/10.1152/ajpendo.00284 .2012

93. Fortin CF, McDonald PP, Fülöp T, Lesur O (2010) Sepsis, leukocytes, and nitric oxide (NO): an intricate affair. Shock 33:344-352. https://doi. org/10.1097/SHK.0b013e3181c0f068

94. Dunn JLM, Hunter RA, Gast K et al (2016) Direct detection of blood nitric oxide reveals a burn-dependent decrease of nitric oxide in response to Pseudomonas aeruginosa infection. Burns 42:1522-1527. https://doi.org/10.1016/j.burns.2016.05.005

95. Winkler MS, Kluge S, Holzmann M et al (2017) Markers of nitric oxide are associated with sepsis severity: an observational study. Crit Care 21:189-199. https://doi.org/10.1186/s13054-017-1782-2

96. Davis JS, Yeo TW, Piera KA et al (2010) Angiopoietin-2 is increased in sepsis and inversely associated with nitric oxide-dependent microvascular reactivity. Crit Care 14:R89-R98. https://doi.org/10.1186/ cC9020

97. Davis JS, Darcy CJ, Yeo TW et al (2011) Asymmetric dimethylarginine, endothelial nitric oxide bioavailability and mortality in sepsis. PLoS ONE 6:e17260. https://doi.org/10.1371/journal.pone.0017260

98. Winkler MS, Nierhaus A, Rösler G et al (2018) Symmetrical (SDMA) and asymmetrical dimethylarginine (ADMA) in sepsis: high plasma levels as combined risk markers for sepsis survival. Crit Care 22:216-310. https:// doi.org/10.1186/s13054-018-2090-1

99. Hansen MB, Rasmussen LS, Garred P et al (2018) Associations of plasma nitrite, L-arginine and asymmetric dimethylarginine with morbidity and mortality in patients with necrotizing soft tissue infections. Shock 49:667-674. https://doi.org/10.1097/SHK.0000000000000975

100. Cauwels A, Buys ES, Thoonen R et al (2009) Nitrite protects against morbidity and mortality associated with TNF- or LPS-induced shock in a soluble guanylate cyclase-dependent manner. J Exp Med 206:29152924. https://doi.org/10.1084/jem.20091236

101. Cauwels A, Brouckaert P (2011) Nitrite regulation of shock. Cardiovasc Res 89:553-559. https://doi.org/10.1093/cvr/cvq317

102. Waltz P, Escobar D, Botero AM, Zuckerbraun BS (2015) Nitrate/nitrite as critical mediators to limit oxidative injury and inflammation. Antioxid Redox Signal 23:328-339. https://doi.org/10.1089/ars.2015.6256

103. Lewington S, Clarke R, Qizilbash N et al (2002) Age-specific relevance of usual blood pressure to vascular mortality: a meta-analysis of individual data for one million adults in 61 prospective studies. Lancet 360:19031913. https://doi.org/10.1016/s0140-6736(02)11911-8

104. Steitieh D, Amin N (2019) Angina pectoris worsened by mouthwash. Proc Bayl Univ Med Cent 32:570-571. https://doi.org/10.1080/08998 280.2019.1631096

105. Milstone AM, Passaretti CL, Perl TM (2008) Chlorhexidine: expanding the armamentarium for infection control and prevention. Clin Infect Dis 46:274-281. https://doi.org/10.1086/524736

106. Zhurakivska K, Troiano G, Caponio VCA et al (2019) Do changes in oral microbiota correlate with plasma nitrite response? A systematic review. Front Physiol 10:1029. https://doi.org/10.3389/fphys.2019.01029

107. Oliveira-Paula GH, Pinheiro LC, Tanus-Santos JE (2019) Mechanisms impairing blood pressure responses to nitrite and nitrate. Nitric Oxide 85:35-43. https://doi.org/10.1016/j.niox.2019.01.015

108. Montenegro MF, Sundqvist ML, Larsen FJ et al (2017) Blood pressurelowering effect of orally ingested nitrite is abolished by a proton pump inhibitor. Hypertension 69:23-31. https://doi.org/10.1161/HYPERTENSI ONAHA. 116.08081

109. Pinheiro LC, Montenegro MF, Amaral JH et al (2012) Increase in gastric $\mathrm{pH}$ reduces hypotensive effect of oral sodium nitrite in rats. Free Radic Biol Med 53:701-709. https://doi.org/10.1016/j.freeradbio med.2012.06.001

110. de Smet AMGA, Kluytmans JAJW, Cooper BS et al (2009) Decontamination of the digestive tract and oropharynx in ICU patients. N Engl J Med 360:20-31. https://doi.org/10.1056/NEJMoa0800394

111. Wittekamp BH, Plantinga NL, Cooper BS et al (2018) Decontamination strategies and bloodstream infections with antibiotic-resistant microorganisms in ventilated patients: a randomized clinical trial. JAMA 320:2087-2098 https://doi.org/10.1001/jama.2018.13765

112. 3M Health Information Systems (2003) All Patient Refined Diagnosis Related Groups (APR-DRGs), Version 20.0, Methodology Overview. https ://www.hcup-us.ahrq.gov/db/nation/nis/APR-DRGsV20MethodologyOv erviewandBibliography.pdf. Accessed 23 May 2017.

113. Lee S, Lighvan NL, McCredie V et al (2019) Chlorhexidine-related mortality rate in critically ill subjects in intensive care units: a systematic review and meta-analysis. Respir Care 64:337-349. https://doi. org/10.4187/respcare.06434

114. Blot S, Vandewoude K, Hoste E et al (2003) Absence of excess mortality in critically ill patients with nosocomial Escherichia coli bacteremia. Infect Control Hosp Epidemiol 24:912-915. https://doi. org/10.1086/502159

115. Kim PW, Perl TM, Keelaghan EF et al (2005) Risk of mortality with a bloodstream infection is higher in the less severely ill at admission. Am J Respir Crit Care Med 171:616-620. https://doi.org/10.1164/ rccm.200407-9160C 
116. Bekaert M, Timsit J-F, Vansteelandt S et al (2011) Attributable mortality of ventilator-associated pneumonia: a reappraisal using causal analysis. Am J Respir Crit Care Med 184:1133-1139. https://doi.org/10.1164/ rccm.201105-08670C
117. Blot S, Vandewoude K, Hoste E, Colardyn F (2003) Reappraisal of attributable mortality in critically ill patients with nosocomial bacteraemia involving Pseudomonas aeruginosa. J Hosp Infect 53:18-24 